\title{
High IFN- $\gamma /$ IL-10 Expression Ratio and Increased Frequency of Persistent Human T-Cell Lymphotropic Virus Type 1-Infected Clones Are Associated with Human T-Cell Lymphotropic Virus Type 1-Associated Myelopathy/Tropical Spastic Paraparesis Development
}

\author{
Otávio M. Espíndola ${ }^{a}$ Luã C. Oliveira ${ }^{a}$ Priscilla M.S. Ferreira ${ }^{a}$ \\ Ana Claudia C.B. Leite ${ }^{b}$ Marco Antonio S.D. Limab, c Maria José Andrada-Serpa ${ }^{a}$ \\ ${ }^{a}$ Laboratory for Research on Viral Pathogenesis, and ${ }^{b}$ Laboratory for Clinical Research on Neuroinfections, \\ Evandro Chagas National Institute of Infectious Diseases - FIOCRUZ, and ' Neurology Department, The Federal University \\ of Rio de Janeiro, Rio de Janeiro, Brazil
}

\section{Key Words \\ Human T-cell lymphotropic virus type $1 \cdot$ Human T-cell lymphotropic virus type 1-associated myelopathy/tropical spastic paraparesis · IFN- $\gamma \cdot$ IL-10 $\cdot$ Clonality $\cdot$ Biological markers}

\begin{abstract}
Background/Aims: Human T-cell lymphotropic virus type 1 (HTLV-1) is a retrovirus that causes a persistent infection, and only $0.5-5 \%$ of infected individuals will develop HTLV-1-associated myelopathy/tropical spastic paraparesis (HAM/ TSP). Therefore, we investigated parameters to discriminate HTLV-1 asymptomatic carriers (ACs) with an increased chance to develop HAM/TSP. Methods: We evaluated integration patterns of HTLV-1 provirus, the relative expression of HTLV- 1 tax and HBZ mRNAs and of IFN- $\gamma$ and IL-10 mRNAs, in addition to proviral load (PVL) levels. Results: HAM/TSP patients presented a higher number of large persistent HTLV-1-carrying clones compared to ACs, and the expression of the HTLV-1 tax and HBZ genes by infected cells was
\end{abstract}

detected at low levels and correlated positively with PVL. In addition, HAM/TSP patients and ACs with high PVL expressed higher levels of IFN- $\gamma$ mRNA in comparison to IL-10, while ACs with low PVL presented an equilibrate IFN- $\gamma / \mathrm{IL}-10$ ratio. Conclusions: The presence of large persistent HTLV1 -infected clones in association with viral gene expression, even at small levels, could stimulate the intense inflammatory response in HTLV-1-infected individuals. This was supported by a high ratio of IFN- $\gamma / \mathrm{IL}-10$ relative expression in $\mathrm{HAM} / \mathrm{TSP}$ patients and ACs with high PVL, indicating that these parameters could aid the identification of ACs with a high risk to develop HAM/TSP.

(c) 2015 S. Karger AG, Basel

\section{Introduction}

Human T-cell lymphotropic virus type 1 (HTLV-1) is a retrovirus that causes a persistent infection, and $0.5-5 \%$ of infected individuals will develop the associated diseases: adult T-cell leukemia/lymphoma [1] and HTLV-1-associ-

\section{KARGER 125}

E-Mail karger@karger.com www.karger.com/int
(C) 2015 S. Karger AG, Basel

$0300-5526 / 15 / 0582-0106 \$ 39.50 / 0$
Otávio de Melo Espíndola, $\mathrm{PhD}$

Laboratório de Pesquisa em Patogenia Viral Instituto Nacional de Infectologia Evandro Chagas - INI-FIOCRUZ Avenida Brasil 4365, Manguinhos - Rio de Janeiro, RJ 21040-900 (Brazil) E-Mail otavio.espindola@ini.fiocruz.br 
ated myelopathy/tropical spastic paraparesis (HAM/TSP) [2]. In contrast, most HTLV-1-infected individuals will remain asymptomatic carriers (ACs) throughout life [2].

HAM/TSP is a demyelinating disease of the spinal cord that initiates as an inflammatory reaction after blood-brain barrier disruption. The immune response is mediated by cytotoxic $\mathrm{T}$ lymphocytes (CTLs) against HTLV-1-infected T cells in the central nervous system, resulting in exacerbated production of Th1 cytokines by activated cells, such as IFN- $\gamma$ and TNF- $\alpha$, which induces the death of central nervous system cells [2, 3]. However, the events or mechanisms that disrupt the asymptomatic condition in HTLV-1 infection and triggers HAM/TSP development are still unknown. It has been shown that high HTLV-1 proviral load (PVL) in peripheral blood is a risk factor for neurological involvement [4].

It has been demonstrated that HTLV-1-infected T-cell clones can persist for many years in patients $[5,6]$, and infected individuals generally carry 500-5,000 distinct infected $\mathrm{T}$-cell clones defined by proviral integration sites [7]. Indeed, clonal expansion of infected cells is responsible for maintaining HTLV-1 PVL levels [8]. In contrast, infected individuals show a chronic and intense response of activated HTLV-1-specific CTLs, which is elicited by persistent expression of viral antigens $[9,10]$. Therefore, expression of HTLV-1 proteins, notably Tax protein, influences both the proliferation of infected cells as their susceptibility to lysis by CTLs [8].

HTLV-1 Tax transactivator protein interacts with different transcription factors, including CREB/ATF, SRF, NFAT, and NF- $\kappa B[11,12]$, thereby regulating the expression of viral genes and the function of different cellular processes, such as cell proliferation, differentiation and death, cytoskeleton reorganization, and DNA repair [1316]. HTLV-1 provirus also presents an antisense gene coding for a negative regulator of Tax functions, denominated HBZ (HTLV-1 basic leucine zipper factor) [17]. HBZ partially represses Tax activity through the competition for association with transcription factors such as CREB [18], CREB-2 [17], and AP-1 [19, 20], and it is important in survival of HTLV-1-transformed cells [21] and in enhancement of in vivo infectivity [22].

Usually, a long interval elapses from the time of infection to disease onset in HTLV-1 carriers, ranging from 20 to 30 years [2]. The development of markers to assist the early identification of HTLV-1 ACs at a higher risk to develop HAM/TSP would allow better clinical monitoring and implementation of therapeutic interventions to delay disease progression. Therefore, we examined the profiles of IFN- $\gamma$ and IL-10 mRNA expression and parameters of
HTLV-1 infection, such as PVL levels, the relative expression of viral tax and $H B Z$ genes, and the pattern of provirus integration sites, in ACs and HAM/TSP patients, to determine biological markers for development of HAM/TSP.

\section{Materials and Methods}

\section{Patients and Samples}

The study was conducted at the Instituto Nacional de Infectologia Evandro Chagas (INI/FIOCRUZ), with approval of the Research Ethics Committee of the INI/FIOCRUZ (CAAE 0013.0.009.000-07) from 2009 to 2013. Forty-six HTLV-1-infected individuals (21 ACs and $25 \mathrm{HAM} / \mathrm{TSP}$ patients) and 12 healthy donors (HDs) were enrolled. After informed consent, peripheral blood was collected in tubes with EDTA or heparin. PBMCs were obtained by centrifugation of heparinized blood on Histopaque 1077 (Sigma-Aldrich), and cells were counted in automatic cell counter (XT1800i, Symex). Cell suspensions were adjusted to $10^{6}$ PBMCs/ml in RPMI-1640 supplemented with $10 \%$ FBS, and $10^{7}$ cells were incubated without stimulation at $37^{\circ}$ for $20 \mathrm{~h}$ in $5 \% \mathrm{CO}_{2}$ atmosphere. Fresh and cultured PBMCs were stored at $-20^{\circ}$ in Trizol reagent (Invitrogen) until use.

DNA Extraction and HTLV-1 PVL

DNA from EDTA peripheral blood was obtained using the Puregene Blood Core kit (Qiagen), following the manufacturer's instructions. HTLV-1 PVL was determined by real-time PCR using TaqMan probes in Smart Cycler II equipment (Cepheid), as previously described [23]. The gene for $\beta$-globin was used as a reference, and infected cells were detected by amplification of the HTLV-1 tax gene. Standard curves to determine the total number of leukocytes and the number of infected cells in reactions were constructed, respectively, with twofold dilutions of human genomic DNA (Promega) and DNA from the HTLV-1-infected TARL-2 cell line. PVL as the frequency of HTLV-1-infected cells in peripheral blood leukocytes was calculated as [(copy number of tax $) /($ copy number of $\beta$-globin/2)] $\times 100$.

Amplification of HTLV-1 Integration Sites by Inverse Long-PCR

Integration sites of HTLV-1 provirus in host-cell DNA was evaluated by inverse long-PCR (IL-PCR), as described by Etoh et al. [5]. Initially, $1 \mu \mathrm{g}$ of DNA from peripheral blood was digested with $5 \mathrm{U}$ EcoRI (New England Biolabs) at $37^{\circ}$ for $2 \mathrm{~h}$. Afterwards, DNA fragments (300 ng) were autocircularized overnight at $4^{\circ}$ with 2 U T4 DNA ligase, in duplicate (New England Biolabs). After purification, circularized DNA was incubated overnight at $37^{\circ}$ with $10 \mathrm{U} M l u \mathrm{I}$ (New England Biolabs). After further purification, the samples were submitted to PCR with a GeneAmp XL PCR kit (Applied Biosystems), using 40 pmol of U3 and U5 LTR-directed primers, under the following amplification cycle: denaturation at $94^{\circ}$ for $1 \mathrm{~min}, 37$ cycles of denaturation at $94^{\circ}$ for $1 \mathrm{~min}$ and annealing/ extension at $68^{\circ}$ for $7 \mathrm{~min}$, and final extension at $72^{\circ}$ for $10 \mathrm{~min}$. Amplicons were electrophoresed in a $1 \%$ agarose gel in $1 \times$ TBE buffer at $80 \mathrm{~V}$ for $3 \mathrm{~h}$ and DNA was stained with GelRed (Biotium). Oligoclonal integration was considered when 2-10 well-defined bands were observed and polyclonal integration was defined when only smear background or more than 10 bands were present. 


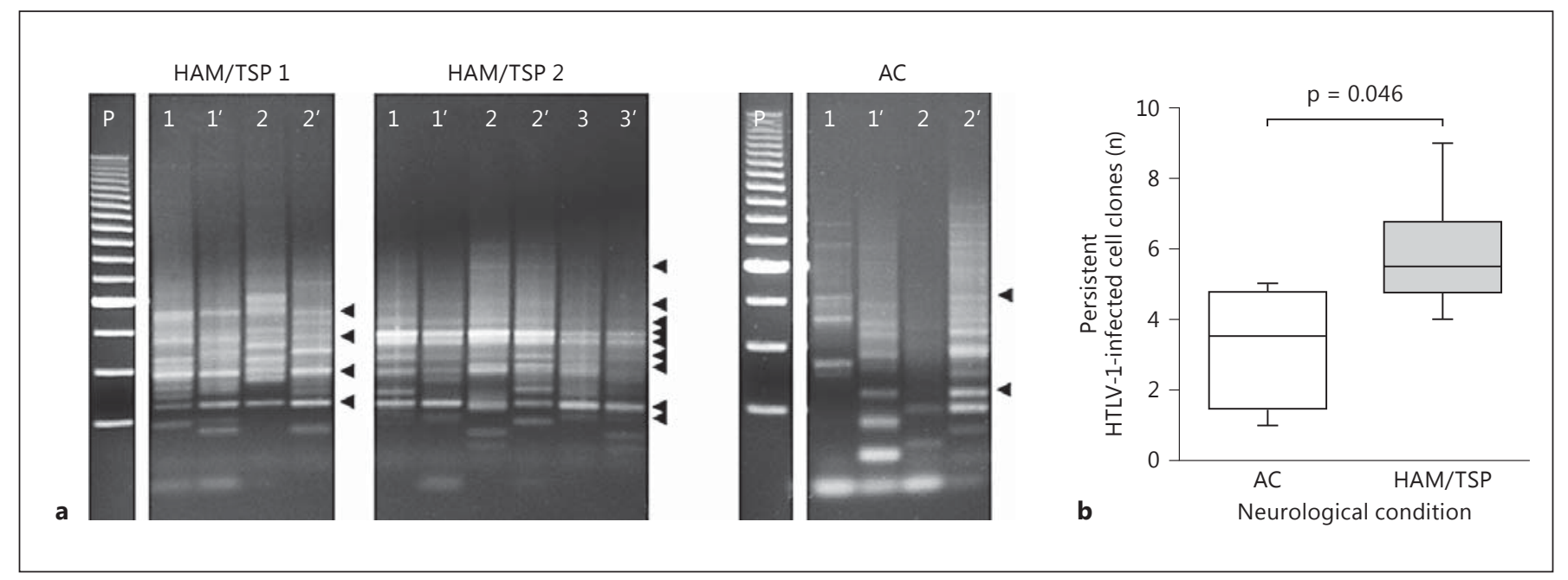

Fig. 1. Persistence of HTLV-1-infected cell clones. a The pattern of HTLV-1 provirus integration was evaluated in peripheral blood leukocytes from HTLV-1 ACs and HAM/TSP patients. DNA samples obtained over an average interval of 36.4 months (95\% CI: 23.1-49.7) were submitted to IL-PCR [23]. Bands visualized on agarose gel after electrophoresis represent large HTLV-1-infected clonal populations when present in both duplicates, while amplification background represent proviral integration sites from mi-

RNA Extraction and Quantitative Reverse Transcription PCR for Gene Expression

Total RNA was extracted from fresh or cultured PBMCs using Trizol reagent, according to manufacturer's instructions, and was readily used for cDNA synthesis with SuperScript III (Invitrogen). Reverse transcription was performed with $2 \mu \mathrm{g}$ of total RNA and random hexamers (Invitrogen) at $50^{\circ}$ for $50 \mathrm{~min}$, in a final volume of $20 \mu \mathrm{l}$. Relative expression of IFN- $\gamma$ and IL-10 mRNAs and of viral tax and HBZ mRNAs was performed by quantitative PCR in Rotor-Gene Q equipment (Qiagen) using the Rotor Gene Probe PCR kit (Qiagen), with $100 \mathrm{ng}$ of cDNA in a final volume of $25 \mu \mathrm{l}$, and GAPDH expression as a reference. The expression of GAPDH, IFN- $\gamma$, and IL-10 mRNAs was evaluated with predesigned TaqMan gene expression assays (Applied Biosystems), HTLV-1 tax cDNAs were amplified as described for PVL quantification, and $H B Z$ expression was detected as previously described [24]. Duplicate reactions were submitted to: activation/denaturation at $95^{\circ}$ for $3 \mathrm{~min}$, 50 cycles of denaturation at $95^{\circ}$ for $5 \mathrm{~s}$, and annealing/extension at $60^{\circ}$ for $15 \mathrm{~s}$; fluorescence was detected at the end of each cycle. Relative gene expression was evaluated by the $2^{-\Delta \Delta \mathrm{Ct}}$ method [25].

\section{Statistical Analysis}

Graphs and statistical analysis were performed using GraphPad Prism 5. After defining the normal distribution of data by Kolmogorov-Smirnov test, parametric data were tested by Pearson correlation, ANOVA, and Student's t test, with Welch's correction when indicated. Nonparametric data were evaluated by Kruskal-Wallis and Mann-Whitney tests and Spearman correlation, and association between qualitative variables was tested by $\chi^{2}$ or Fisher's exact test. Results with $\mathrm{p}<0.05$ were considered statistically significant. nority clones. Results are representative of $6 \mathrm{HAM} / \mathrm{TSP}$ patients and 5 ACs. Arrowheads indicate large persistent HTLV-1 provirus-carrying clones. P, 500-bp DNA ladder. b The frequency of these large persistent HTLV-1-infected clones was determined by visualization of the same band size in consecutive samples in at least one of duplicates. Differences in mean number of persistent clones between ACs and HAM/TSP patients were calculated by Student's t test.

\section{Results}

\section{HTLV-1 Provirus Integration Pattern and Persistence} of Infected Cell Clones

DNA samples from HAM/TSP patients $(n=6)$ and ACs $(\mathrm{n}=5)$ with similar high PVL levels (HAM/TSP: $20.60 \pm 15.31 \%$ and ACs: $12.35 \pm 1.25 \%$; $p=0.246$, Student's t test with Welch's correction) obtained in two or three distinct periods with a mean interval of 36.4 months (95\% CI: 23.1-49.7) between the first and last sample were used to evaluate HTLV-1 provirus integration by ILPCR. Both HAM/TSP patients and ACs showed predominantly stochastic patterns of proviral integration. In ILPCR, the amplification background in agarose gel electrophoresis represents minor clones, while clear bands are related to large HTLV-1-infected clonal populations (fig. 1a). The integration profile was oligoclonal in all 6 HAM/TSP patients and in 3 of 5 ACs. Therefore, no association was observed between the integration pattern of HTLV-1 and the clinical condition of the evaluated subjects ( $p=0.189$, Fisher's exact test). On the other hand, chronic HAM/TSP patients (mean disease duration of 14 \pm 8.1 years) presented higher frequency of large persistent HTLV-1-infected clones (5.82 \pm 1.71 clones) compared to ACs (3.25 \pm 1.72 clones; $\mathrm{p}=0.046$; fig. $1 \mathrm{~b})$. 


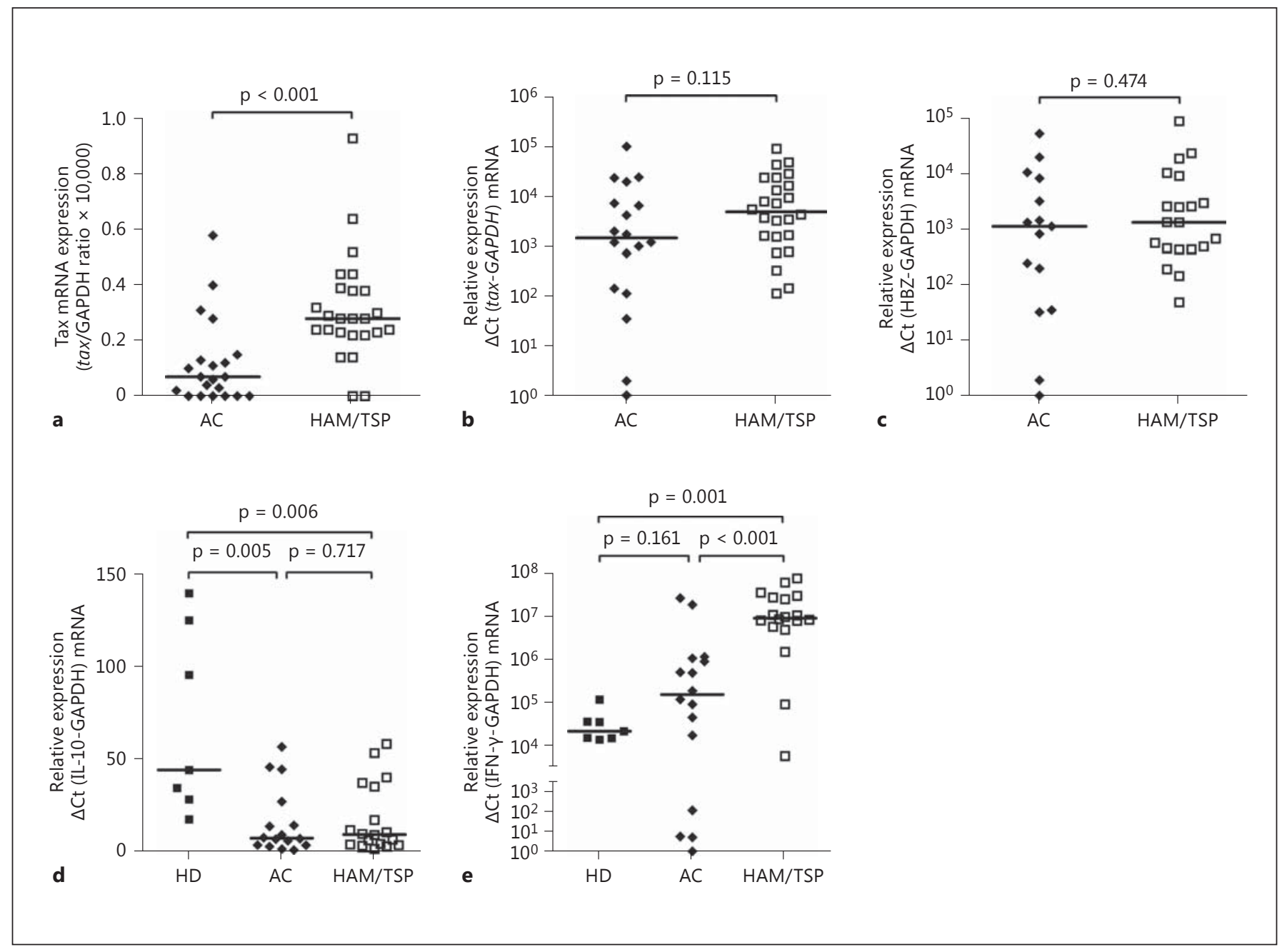

Fig. 2. Relative expression of HTLV-1 tax, and IFN- $\gamma$ and IL-10 mRNAs. a Expression of tax mRNAs was evaluated in fresh PBMCs from HTLV-1 ACs $(\mathrm{n}=21)$ and HAM/TSP patients $(\mathrm{n}=$ 25 ), and values were arbitrarily multiplied by 10,000 . b The expression of tax mRNAs was also further evaluated in PBMCs from ACs $(\mathrm{n}=18)$ and HAM/TSP patients $(\mathrm{n}=24)$ after $20 \mathrm{~h}$ of incubation without stimulation. $c$ The relative expression of $H B Z$ mRNAs was performed in PBMCs from ACs $(n=15)$ and HAM/TSP patients $(\mathrm{n}=20)$, while the expression of IL-10 (d) and IFN- $\gamma(\mathbf{e})$ mRNAs was evaluated in PBMCs from ACs $(\mathrm{n}=16)$, HAM/TSP patients $(\mathrm{n}=18)$, and HDs $(\mathrm{n}=7)$ after $20 \mathrm{~h}$ of incubation without stimulation. GAPDH expression rates were used to normalize values. In b-e, after conversion of $\log (2)$ data to linear scale, the lowest value obtained in each analysis was arbitrated as equal to 1 . Statistical analysis was performed with Mann-Whitney test, and results with $\mathrm{p}<0.05$ were considered statistically significant.

\section{Expression of HTLV-1 tax and HBZ mRNAs in} PBMCs from Infected Individuals

In the same way that chronic HAM/TSP patients exhibited higher PVL median than ACs [6.28\% (95\% CI: 7.24-13.11) and 4.31\% (95\% CI: 3.38-7.27), respectively, Mann-Whitney, $\mathrm{p}=0.002$ ] and higher frequency of large persistent HTLV-1-infected clonal populations (fig. 1b), these individuals also showed higher relative expression of tax mRNAs by fresh PBMCs in comparison to ACs ( $\mathrm{p}<0.001$; fig. 2a). However, the HTLV-1 tax gene was weakly expressed ex vivo. Expression of tax mRNAs was 10,000-100,000 times lower than basal cellular transcription levels defined by GAPDH expression. The expression of tax mRNAs was upregulated after overnight incubation of PBMCs without stimulation. However, statistically significant differences between ACs and HAM/TSP patients disappeared (fig. 2b). On the other side, $H B Z$ mRNA expression was evaluated only in PBMC incubated for $20 \mathrm{~h}$ without stimulation, because it is expressed at low levels. Although $\mathrm{HBZ}$ 


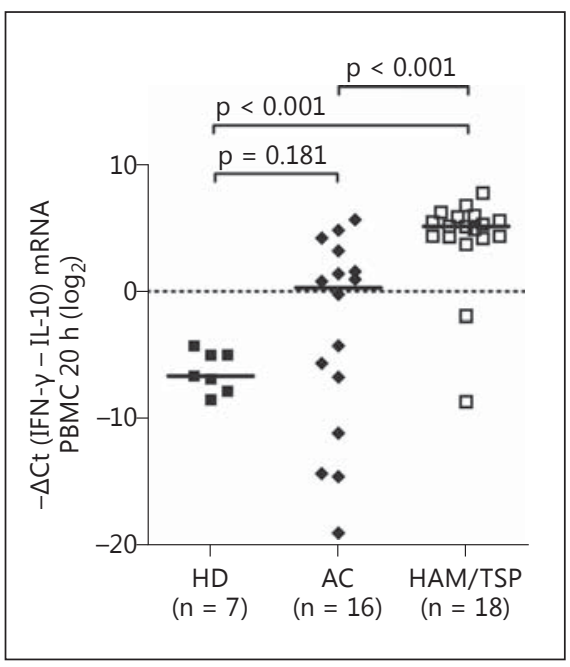

Fig. 3. Difference between IFN- $\gamma$ and IL-10 mRNAs expression levels in PBMCs from HTLV-1 ACs, HAM/TSP patients, and HDs. Variation in relative expression of these genes was calculated as $-\Delta \mathrm{Ct}=\left(\right.$ mean $\mathrm{Ct}_{\mathrm{IFN}-\gamma}-$ mean $\left.\mathrm{Ct}_{\mathrm{IL}-10}\right)$. Statistical significance was determined by a Mann-Whitney test.

mRNA expression in PBMCs were 3.01 times higher in HAM/TSP patients than ACs (table 1), this difference was not significant ( $p=0.474$, Mann-Whitney; fig. $2 c)$, even when it was corrected with PVL levels $(\mathrm{p}=0.594$, Mann-Whitney).

\section{IL-10 and IFN- $\gamma$ mRNA Expression in PBMCs from HTLV-1-Infected Individuals}

Differences in relative expression of IL-10 mRNAs were not observed between ACs and HAM/TSP patients ( $\mathrm{p}=$ 0.717; fig. 2d). However, both ACs and HAM/TSP patients presented reduced IL-10 mRNA expression in comparison to uninfected individuals $(\mathrm{p}=0.005$ and $\mathrm{p}=0.006$, respectively). On the other hand, HAM/TSP patients showed increased levels of IFN- $\gamma$ expression compared to ACs ( $\mathrm{p}<$ 0.001 ) and HDs ( $p=0.001$; fig. 2e), but no differences were observed between ACs and HDs $(\mathrm{p}=0.161)$. The ratio between IFN- $\gamma$ and IL-10 mRNA relative expression levels was also investigated by calculating the $-\Delta \mathrm{Ct}$ (mean $\mathrm{Ct}_{\mathrm{IFN}-\gamma}-\mathrm{mean}_{\mathrm{Ct}} \mathrm{IL}-10_{10}$ (fig. 3), taking that commercial realtime PCR for these genes presented similar efficiency rates. On average, HAM/TSP patients expressed more IFN- $\gamma$ than IL-10 ( $-\Delta \mathrm{Ct}=5.10$ or 34.30 times), while ACs presented balanced levels of expression of both cytokines $(-\Delta \mathrm{Ct}=0.27)$. In contrast, HDs expressed more IL-10 instead of IFN- $\gamma(-\Delta \mathrm{Ct}=-6.61$ or 97.68 times $)$. However, differences were statistically significant only in HAM/TSP patients (fig. 3).
Table 1. Relative expression of HBZ mRNAs in ACs and HAM/ TSP patients

\begin{tabular}{|c|c|c|}
\hline & $\mathrm{AC}$ & HAM/TSP \\
\hline $\mathrm{Ct}_{H B Z}$ & $34.03 \pm 4.47$ & $32.48 \pm 2.75$ \\
\hline $\mathrm{Ct}_{G A P D H}$ & $18.18 \pm 0.81$ & $18.08 \pm 0.75$ \\
\hline$\Delta \mathrm{Ct}^{\mathrm{a}}$ & $16.04 \pm 4.63$ & $14.45 \pm 2.72$ \\
\hline$\Delta \Delta \mathrm{Ct}^{\mathrm{b}}$ & $0.00 \pm 4.63$ & $-1.59 \pm 2.72$ \\
\hline $\begin{array}{l}\text { Normalized expression } \\
\quad\left(2^{-\Delta \Delta \mathrm{Ct}}\right)\end{array}$ & $1.00(0.04-24.76)$ & $3.01(2.19-19.84)$ \\
\hline
\end{tabular}

Relative expression of $H B Z$ mRNAs in PBMCs incubated for $20 \mathrm{~h}$ without stimulation, from HTLV-1 ACs and HAM/TSP patients was determined by the $2^{-\Delta \Delta C t}$ method [25].

Values are presented as means $\pm \mathrm{SD}$. Ct $=$ Cycle threshold.

${ }^{\text {a }}$ Mean $\mathrm{Ct}_{\mathrm{HBZ}}$ - mean $\mathrm{Ct}_{\text {GAPDH }}$.

${ }^{\mathrm{b}}$ Mean $\Delta \mathrm{Ct}_{\mathrm{HAM} / \mathrm{TSP}}-$ mean $\Delta \mathrm{Ct}_{\mathrm{AC}}$.

Table 2. Correlation between tax, HBZ, IL-10, and IFN- $\gamma$ gene expression and PVL

\begin{tabular}{lllr}
\hline Genes & Samples, $\mathrm{n}$ & $\begin{array}{l}\text { Correlation } \\
\text { coefficient, } R^{\mathrm{a}}\end{array}$ & $\mathrm{p}$ \\
\hline tax & & & \\
AC & 21 & 0.817 & $<0.001$ \\
HAM/TSP & 25 & 0.433 & 0.031 \\
Total & 46 & 0.730 & $<0.001$ \\
HBZ & & & \\
AC & 15 & 0.557 & 0.031 \\
HAM/TSP & 20 & 0.803 & $<0.001$ \\
Total & 35 & 0.655 & $<0.001$ \\
IL-10 & 16 & -0.410 & 0.115 \\
AC & 18 & 0.313 & 0.207 \\
HAM/TSP & 34 & -0.009 & 0.958 \\
Total & & & \\
IFN- $\gamma$ & 16 & 0.321 & 0.225 \\
AC & 18 & 0.682 & 0.002 \\
HAM/TSP & 34 & 0.672 & $<0.001$ \\
Total & & & \\
\hline
\end{tabular}

Correlation between relative expression rates of tax, HBZ, IL10 , and IFN- $\gamma$ mRNAs and HTLV-1 PVL levels in HTLV-1 ACs and in HAM/TSP patients was evaluated by Spearman correlation, and $\mathrm{p}<0.05$ was considered statistically significant. ${ }^{\mathrm{a}} R=$ Correlation coefficient of Spearman.

Correlation between HTLV-1 PVL and Expression of

Tax, HBZ, IL-10, and IFN- $\gamma$ mRNAs

The expression of viral and cytokine mRNAs was also assessed according to HTLV-1 PVL levels. It was observed that expression of tax mRNAs in fresh PBMCs and 


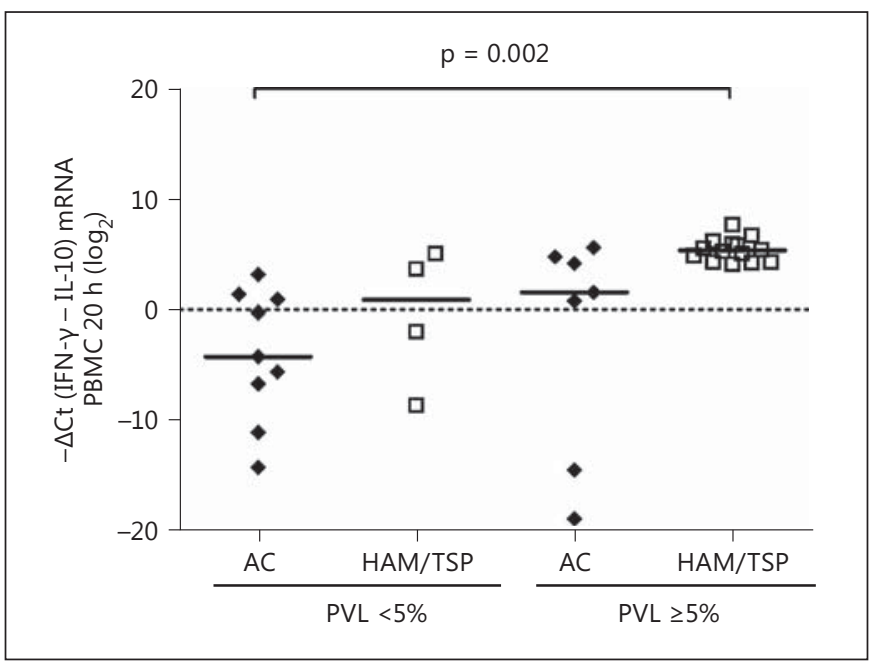

Fig. 4. Association between IFN- $\gamma / \mathrm{IL}-10$ mRNA expression ratios and neurological condition of HTLV-1-infected individuals with distinct HTLV-1 PVL levels. HTLV-1 ACs and HAM/TSP patients were subdivided according to PVL levels (low: $<5 \%$ and high: $\geq 5 \%)$ and $-\Delta \mathrm{Ct}_{(\mathrm{IFN}-\gamma-\mathrm{IL}-10)}$ values were compared. Statistical analysis was performed by Student's t test with Welch's correction.

Table 3. Association between IFN- $\gamma / \mathrm{IL}-10$ mRNA expression ratios and neurological involvement in HTLV-1-infected individuals

\begin{tabular}{cccc}
\hline & \multicolumn{2}{c}{ Clinical status } & \multirow{2}{*}{ Total } \\
\cline { 2 - 3 } & AC & \\
\hline$-\Delta C t($ IFN- $\gamma-$ IL-10) & & & \\
$(+)$ & 8 & 16 & 24 \\
$(-)$ & 8 & 2 & 10 \\
Total & 16 & 18 & 34 \\
\hline
\end{tabular}

The $-\Delta \mathrm{Ct}(\mathrm{IFN}-\gamma-\mathrm{IL}-10)$-positive $(+)$ results indicate individuals in which IFN- $\gamma$ expression exceeded IL-10 mRNA levels, and negative (-) results indicate individuals with IFN $-\gamma$ mRNA expression lower than IL-10 levels. Differences between HTLV-1 ACs and HAM/TSP patients were evaluated by a $\chi^{2}$ test $[\mathrm{p}=0.023$ and $\mathrm{OR}=8.00(95 \% \mathrm{CI}: 1.37-46.81)]$.

that of $H B Z$ mRNAs positively correlated with PVL, regardless of neurological involvement (table 2). Considering the tax expression levels after incubation of the cells without stimulation, correlation with PVL remained only in the group of HAM/TSP patients (Spearman $R=0.624$, $\mathrm{p}=0.001$ ), while it was no longer present in ACs (Spear$\operatorname{man} R=0.366, \mathrm{p}=0.136$; data not shown). With respect to expression of cytokine genes, correlation between IL10 mRNA expression and HTLV-1 PVL was not observed in either ACs $(p=0.115)$ or HAM/TSP patients $(\mathrm{p}=$

High IFN- $\gamma /$ IL-10 Ratio and HAM/TSP
0.313 ; table 2). On the other hand, expression of proinflammatory cytokine IFN- $\gamma$ positively correlated with PVL only in HAM/TSP patients ( $\mathrm{p}=0.002$; table 2$)$.

\section{Association between IFN- $\gamma /$ IL-10 Expression Ratio} and the Neurological Involvement

Since high HTLV-1 PVL has been associated with a higher chance of neurological involvement, HTLV-1-infected individuals were subdivided according to PVL levels: low $(<5 \%)$ and high $(\geq 5 \%)$. We observed that HAM/TSP patients with low PVL and ACs with high PVL presented an IFN- $\gamma / \mathrm{IL}-10 \mathrm{mRNA}$ ratio tending towards zero, indicating that both cytokines are expressed in equivalent levels (fig. 4). These data suggest that ACs with high HTLV-1 PVL present an inflammatory profile similar to that of HAM/ TSP patients. On the other hand, HAM/TSP patients with high PVL presented higher levels of IFN- $\gamma$ against IL-10, with median $-\Delta \mathrm{Ct}_{(\mathrm{IFN}-\gamma-\mathrm{IL}-10)}$ significantly higher than ACs with low PVL $(\mathrm{p}=0.002)$, which in turn expressed lower levels of IFN- $\gamma$ (fig. 4). The ratio between IFN- $\gamma$ and IL-10 mRNA expression did not correlate with HTLV-1 PVL levels in either ACs $\left(R^{2}=0.115 ; \mathrm{p}=0.199\right.$, Spearman correlation) or HAM/TSP patients $\left(R^{2}=0.078 ; \mathrm{p}=0.261\right.$, Spearman correlation). It was also an independent variable from PVL in the AC group ( $p=0.315$, Fisher's exact test). However, a high IFN- $\gamma / \mathrm{IL}-10$ expression ratio was associated with neurological involvement in HTLV-1-infected individuals $\left(\mathrm{p}=0.023\right.$ and $\mathrm{OR}=8.00, \chi^{2}$ test; table 3 ).

\section{Discussion}

$\mathrm{HAM} / \mathrm{TSP}$ is a slowly progressive incapacitating disease of lower limbs and usually presents an insidious onset [2]. It has been shown that HAM/TSP patients present higher HTLV-1 PVL levels than ACs, and therefore it has been proposed as a marker for monitoring evolution to disease [23]. Usually, it is observed that circulating HTLV1 -infected clones contain a single integrated proviral copy [26], and PVL levels are maintained mainly through expansion of these cells [4]. We observed that both ACs and HAM/TSP patients with high HTLV-1 PVL presented large HTLV-1-infected clonal populations in peripheral blood, and some of them were capable of persisting over time, corroborating other reports [7,26]. PVL levels have been associated with the number of HTLV-1-infected clones both in ACs and HAM/TSP patients, and HAM/ TSP patients present increased absolute numbers of HTLV-1-infected clones, which explain the higher PVL levels in these individuals [7]. However, PVL is achieved 
by a dynamic process, involving the proliferation of infected cells and their elimination by immune responses. Therefore, within a relatively constant PVL level, it can become more oligoclonal over time. Thus, complementing these observations, we showed that large persistent infected clonal populations were at higher frequency in HAM/TSP patients than in ACs with similar PVL levels. It has been shown that in clones of equivalent abundance, integration sites in genes and active regions are more frequent in ACs than patients with HAM/TSP [27], and thus more likely to express viral antigens. Therefore, the lower number of large HTLV-1-infected clones that we observed in ACs in comparison to HAM/TSP patients over time is probably associated with elimination of antigenexpressing infected cells by immune responses, which have been shown to be more effective in ACs than in HAM/TSP patients [4].

We also observed that viral expression in vivo occurs at low levels, about 10,000-100,000 times lower than cellular GAPDH transcription rates. Furthermore, PBMCs from HAM/TSP patients presented higher expression of tax mRNAs in comparison to ACs, and this positively correlated with PVL. It is well known that incubation of infected cells without stimulation is sufficient to induce provirus expression. However, here we showed that in vivo differences between ACs and HAM/TSP patients were lost after cell incubation, and also the correlation with PVL considering the $\mathrm{AC}$ group. $\mathrm{HBZ}$ is fairly expressed in vivo, and we observed no significant differences in $H B Z$ mRNA expression between ACs and HAM/TSP patients, probably due to incubation, although it positively correlated with PVL. Despite the strong CTL response commonly observed against the Tax protein, it has been shown that individuals presenting HLA class I alleles that strongly bind the HBZ protein have lower PVL levels and are more likely to persist asymptomatically due to effective responses of CD8+ T cells specific to HBZ [28]. Therefore, although the expression of HTLV-1 genes influence both proliferation of infected cells and their elimination by exposure to CTLs, the quality of the response appears to determine the outcome of disease. Therefore, we suggest that a higher frequency of large persistent HTLV-1-infected clonal populations would contribute to higher PVL levels usually observed in HAM/TSP patients. Furthermore, persistent expression of viral antigens, even at low concentrations, by infected cells would act as a constant stimulus for the chronic HTLV-1-specific CTL responses [9, 10] that are involved in HAM/TSP onset [2].

It has been reported that HTLV-1 is characterized by a strong Th1 response [29], and PBMCs from HAM/TSP patients secrete high levels of IL-2 and IFN- $\gamma$ in vitro compared to ACs [30]. Moreover, it has been demonstrated that HAM/TSP patients also present a high frequency of $\mathrm{CD} 4^{+} \mathrm{IFN}-\gamma^{+} \mathrm{T}$ cells that positively correlates with HTLV-1 PVL $[31,32]$. We also found that PBMCs from HAM/TSP patients presented increased levels of IFN- $\gamma$ mRNAs in comparison to both ACs and HDs. Furthermore, induction of IFN- $\gamma$ gene expression was directly related to infection because it positively correlated to PVL at least in HAM/TSP patients. In contrast, no significant differences in expression of IL-10 mRNAs were observed between ACs and HAM/TSP patients. Our observations are in agreement with other reports in which differences in levels of IL-10 mRNA expression were not evidenced between ACs and HAM/TSP patients in vitro [33], in serum samples [34], or in cerebrospinal fluid [35]. However, unlike recent published data [34], we showed that PBMCs from HTLV-1-infected individuals, regardless of neurological condition, expressed significantly lower IL-10 mRNA levels than healthy subjects. This difference probably relies on distinct methods to address IL10 expression since previous findings represented the quantification of cytokine protein levels in serum, in contrast to our data from mRNA expression. Since IFN- $\gamma$ is associated with inflammatory conditions and we observed an inversely proportional tendency between HTLV-1 PVL and the expression levels of the immunosuppressive IL-10 cytokine, which suggests that this cytokine could influence the maintenance of asymptomatic status, we evaluated the ratio between IFN- $\gamma$ and IL10 mRNA relative expression. In this context, we observed three distinct patterns: (1) uninfected individuals with significantly higher levels of IL-10 than IFN- $\gamma$, (2) HTLV-1 ACs with equivalent mean mRNA levels of IFN- $\gamma$ and IL-10, and (3) HAM/TSP patients with higher expression levels of IFN- $\gamma$ in comparison to IL- 10 .

Hence, since HAM/TSP patients present higher PVL levels than AC and it has been associated with an increased risk for neurological involvement [23], and IFN- $\gamma$ gene expression correlated with PVL, we assessed the association between the inflammatory status defined by the ratio between IFN- $\gamma$ and IL-10 mRNA relative expression and the neurological condition in HTLV-1-infected individuals according to low or high HTLV-1 PVL levels. We identified distinct patterns, in which HTLV-1-infected subjects expressing higher levels of IFN- $\gamma$ than IL- 10 were 8 times more likely to present HAM/TSP, demonstrating that a proinflammatory condition is a characteristic factor of the immunological profile of these patients. In addition, we observed that ACs tend to present higher IFN- $\gamma$ 
expression rates than uninfected individuals, although it was not statistically significant. This indicates that despite the lack of disease manifestation, these individuals present slight signs of inflammation but less striking than in HAM/TSP patients.

In addition, ACs with high PVL presented inflammatory profiles similar to HAM/TSP patients, in accordance to previous studies $[36,37]$, but only to HAM/TSP patients with low PVL, indicating that factors other than PVL are involved in disease outcome. Since not all HAM/ TSP patients present high PVL, the additional evaluation of the inflammatory profile considering the ratio between IFN- $\gamma$ and IL-10 mRNA expression could aid the identification of ACs at a higher risk for development of HAM/ TSP irrespective of the PVL level. However, longitudinal studies are still needed to answer this.

\section{Acknowledgments}

We thank the patients and volunteers who participated in this study. The authors also thank Dr. Ana Carolina Vicente from Instituto Oswaldo Cruz/FIOCRUZ, Dr. Cynthia Horn from INI/ FIOCRUZ, and Dr. Juliana Echevarria-Lima from Federal University of Rio de Janeiro (UFRJ) for their helpful discussions. This work was supported by the Conselho Nacional de Desenvolvimento Científico e Tecnológico (CNPq) (grant to M.J.A.-S.) and the Fundação de Amparo à Pesquisa do Estado do Rio de Janeiro (FAPERJ) (Grant E26/171.389/2006 to M.J.A.-S.).

\section{Disclosure Statement}

All authors have no conflicts of interest regarding the work reported in this paper.

\section{References}

1 Yoshida M: Discovery of HTLV-1, the first human retrovirus, its unique regulatory mechanisms, and insights into pathogenesis. Oncogene 2006;24:5931-5937.

2 Araújo AQ, Silva MT: The HTLV-1 neurological complex. Lancet Neurol 2006;5:10681076.

3 Lepoutre V, Jain P, Quann K, Wigdahl B, Khan ZK: Role of resident CNS cell populations in HTLV-1-associated neuroinflammatory disease. Front Biosci 2009; 14:11521168.

4 Bangham CR, Meekings K, Toulza F, Nejmeddine M, Majorovits E, Asquith B, Taylor GP: The immune control of HTLV-1 infection: selection forces and dynamics. Front Biosci 2009;14:2889-2903.

5 Etoh K, Tamiya S, Yamaguchi K, Okayama A, Tsubouchi H, Ideta T, Mueller N, Takatsuki K, Matsuoka M: Persistent clonal proliferation of human T-lymphotropic virus type Iinfected cells in vivo. Cancer Res 1997;57: $4862-4867$.

6 Cavrois M, Leclercq I, Gout O, Gessain A, Wain-Hobson S, Wattel E: Persistent oligoclonal expansion of human T-cell leukemia virus type 1-infected circulating cells in patients with tropical spastic paraparesis/ HTLV-1 associated myelopathy. Oncogene $1998 ; 17: 77-82$

7 Gillet NA, Malani N, Melamed A, Gormley N, Carter R, Bentley D, Berry C, Bushman FD, Taylor GP, Bangham CR: The host genomic environment of the provirus determines the abundance of HTLV-1-infected T-cell clones. Blood 2011;117:3113-3122.

8 Bangham CR, Osame M: Cellular immune response to HTLV-1. Oncogene 2005;24:60356046.
9 Daenke S, Kermode AG, Hall SE, Taylor G, Weber J, Nightingale S, Bangham CR: High activated and memory cytotoxic T-cell responses to HTLV-1 in healthy carriers and patients with tropical spastic paraparesis. Virology 1996;217:139-146.

10 Kattan T, MacNamara A, Rowan AG, Nose H, Mosley AJ, Tanaka Y, Taylor GP, Asquith B, Bangham CR: The avidity and lytic efficiency of the CTL response to HTLV-1. J Immunol 2009;182:5723-5729.

11 Azran I, Schavinsky-Khrapunsky Y, Aboud M: Role of Tax protein in human T-cell leukemia virus type-I leukemogenicity. Retrovirology 2004;1:20.

12 Boxus M, Twizere JC, Legros S, Dewulf JF, Kettmann R, Willems L: The HTLV-1 Tax interactome. Retrovirology 2008;5:76.

13 Nejmeddine M, Barnard AL, Tanaka Y, Taylor GP, Bangham CR: Human T-lymphotropic virus, type 1 , tax protein triggers microtubule reorientation in the virological synapse. J Biol Chem 2005;280:29653-29660.

14 Neuveut C, Jeang KT: HTLV-I Tax and cell cycle progression. Prog Cell Cycle Res 2000;4: 157-162.

15 Saggioro D: Anti-apoptotic effect of Tax: an NF-kB path or a CREB way? Viruses 2011;3: 1001-1014.

$16 \mathrm{Wu} \mathrm{K}$, Bottazzi ME, de la Fuente C, Deng L, Gitlin SD, Maddukuri A, Dadgar S, Li H, Vertes A, Pumfery A, Kashanchi F: Protein profile of tax-associated complexes. J Biol Chem 2004;279:495-508.

17 Gaudray G, Gachon F, Basbous J, BiardPiechaczyk M, Devaux C, Mesnard JM: The complementary strand of HTLV-1 RNA genome encodes a bZIP transcription factor that down-regulates the viral transcription. J Virol 2002;76:12813-12822.
18 Lemasson I, Lewis MR, Polakowski N, Hivin $\mathrm{P}$, Cavanagh MH, Thébault S, Barbeau B, Nyborg JK, Mesnard JM: Human T-cell leukemia virus type 1 (HTLV-1) bZIP protein interacts with the cellular transcription factor CREB to inhibit HTLV-1 transcription. J Virol 2007;81:1543-1553.

19 Basbous J, Arpin C, Gaudray G, Piechaczyk M, Devaux C, Mesnard JM: The HBZ factor of human T-cell leukemia virus type I dimerizes with transcription factors JunB and c-Jun and modulates their transcriptional activity. J Biol Chem 2003;278:43620-43627.

20 Matsumoto J, Ohshima T, Isono O, Shimotohno K: HTLV-1 HBZ suppresses AP-1 activity by impairing both the DNA-binding ability and the stability of c-Jun protein. Oncogene 2005;24:1001-1010.

21 Satou Y, Yasunaga J, Yoshida M, Matsuoka M: HTLV-I basic leucine zipper factor gene mRNA supports proliferation of adult T cell leukemia cells. Proc Natl Acad Sci USA 2006; 103:720-725.

22 Arnold J, Yamamoto B, Li M, Phipps AJ, Younis I, Lairmore MD, Green PL: Enhancement of infectivity and persistence in vivo by HBZ, a natural antisense coded protein of HTLV-1. Blood 2006; 107:3976-3982.

23 Silva MT, Harab RC, Leite AC, Schor D, Araújo A, Andrada-Serpa MJ: Human T lymphotropic virus type 1 (HTLV-1) proviral load in asymptomatic carriers, HTLV-1-associated myelopathy/tropical spastic paraparesis, and other neurological abnormalities associated with HTLV-1 infection. Clin Infect Dis 2007;44:689-692. 
24 Saito M, Matsuzaki T, Satou Y, Yasunaga J, Saito K, Arimura K, Matsuoka M, Ohara Y: In vivo expression of the HBZ gene of HTLV-1 correlates with proviral load, inflammatory markers and disease severity in HTLV-1 associated myelopathy/tropical spastic paraparesis (HAM/TSP). Retrovirology 2009;6:19.

25 Livak KJ, Schmittgen TD: Analysis of relative gene expression data using real-time quantitative PCR and the 2(-Delta Delta C(T)) method. Methods 2001;25:402-408.

26 Cook LB, Rowan AG, Melamed A, Taylor GP, Bangham CR: HTLV-1-infected T cells contain a single integrated provirus in natural infection. Blood 2012;120:3488-3490.

27 Niederer HA, Laydon DJ, Melamed A, Elemans M, Asquith B, Matsuoka M, Bangham CR. HTLV-1 proviral integration sites differ between asymptomatic carriers and patients with HAM/TSP. Virol J 2014;11:172.

28 Macnamara A, Rowan A, Hilburn S, Kadolsky U, Fujiwara H, Suemori K, Yasukawa M, Taylor G, Bangham CR, Asquith B: HLA class I binding of $\mathrm{HBZ}$ determines outcome in HTLV-1 infection. PLoS Pathog 2010; 6:e1001117.

29 Porto AF, Neva FA, Bittencourt H, Lisboa W, Thompson R, Alcântara L, Carvalho EM: HTLV-1 decreases Th2 type of immune re- sponse in patients with strongyloidiasis. Parasite Immunol 2001;23:503-507.

30 Carvalho EM, Bacellar O, Porto AF, Braga S, Galvão-Castro B, Neva F: Cytokine profile and immunomodulation in asymptomatic human T-lymphotropic virus type 1-infected blood donors. J Acquir Immune Defic Syndr 2001;27:1-6.

31 Mitre E, Thompson RW, Carvalho EM, Nutman TB, Neva FA: Majority of interferongamma-producing CD4+ cells in patients infected with human $\mathrm{T}$ cell lymphotrophic virus do not express tax protein. J Infect Dis 2003; 188:428-432.

32 Yamano Y, Araya N, Sato T, Utsunomiya A, Azakami K, Hasegawa D, Izumi T, Fujita $\mathrm{H}$, Aratani S, Yagishita N, Fujii R, Nishioka K, Jacobson S, Nakajima T: Abnormally high levels of virus-infected IFN-gamma+ CCR4+ $\mathrm{CD} 4+\mathrm{CD} 25+\mathrm{T}$ cells in a retrovirus-associated neuroinflammatory disorder. PLoS One 2009;4:e6517.

33 Montanheiro PA, Penalva de Oliveira AC Smid J, Fukumori LM, Olah I, da S Duarte AJ, Casseb J: The elevated interferon gamma production is an important immunological marker in HAM/TSP pathogenesis. Scand J Immunol 2009;70:403-407.

34 Starling AL, Martins-Filho OA, Lambertucci JR, Labanca L, de Souza Pereira SR, Teixeira-
Carvalho A, Martins ML, Ribas JG, CarneiroProietti AB, Gonçalves DU: Proviral load and the balance of serum cytocines in HTLV-1asymptomatic infection and in HTLV-1-associated myelopathy/tropical spastic paraparesis (HAM/TSP). Acta Trop 2013;125:7581.

35 Gonçalves DU, Proietti FA, Barbosa-Stancioli EF, Martins ML, Ribas JG, Martins-Filho OA, Teixeira-Carvalho A, Peruhype-Magalhães V, Carneiro-Proietti AB: HTLV-1-associated myelopathy/tropical spastic paraparesis (HAM/TSP) inflammatory network. Inflamm Allergy Drug Targets 2008;7:98-107.

36 Andrade RG, Gonçalves P de C, Ribeiro MA, Romanelli LC, Ribas JG, Torres EB, CarneiroProietti AB, Barbosa-Stancioli EF, Martins ML: Strong correlation between tax and HBZ mRNA expression in HAM/TSP patients: distinct markers for the neurologic disease. J Clin Virol 2013;56:135-140.

37 Best I, López G, Verdonck K, González E, Tipismana M, Gotuzzo E, Vanham G, Clark D: IFN-gamma production in response to Tax 161-233, and frequency of CD4+ Foxp3+ and Lin HLA-DRhigh CD123+ cells, discriminate HAM/TSP patients from asymptomatic HTLV-1-carriers in a Peruvian population. Immunology 2009;128(1 suppl): e777-e786. 